\title{
Study on Effective Using of Multimedia Teaching System and Enhancing Teaching Effect
}

https://doi.org/10.3991/ijet.v12i06.7093

\author{
Xianhong Xu \\ Hubei Polytechnic University, Huangshi, Hubei, China \\ 573852630 @qq. com
}

\begin{abstract}
Through the method of questionnaire survey about multimedia teaching form, some ubiquitous problems have been reflected such as cognitive deviation, blind using, the poor quality of courseware, the poor activity of classroom, etc. The expected effect of multimedia teaching cannot be achieved, and the effectiveness of multimedia teaching is faced with some suspicions. The effectiveness of multimedia teaching contains two aspects: effective using of multimedia teaching system and the effectiveness of teaching effect. We should enhance management and direction, correctly understand and reasonably treat multimedia teaching, avoid the blindness of multimedia construction and use, increase the quality of courseware, promote teacher's professional level and classroom dynamics, organically combine traditional and multimedia teaching, and take a series of measures to improve the effectiveness of multimedia teaching.
\end{abstract}

Keywords-multimedia teaching, teaching effect, effectiveness

\section{$1 \quad$ Introduction}

With the development of education informatization, the multimedia teaching has been more and more widely used in schools, education and institutions of various levels. Multimedia teaching has many advantages of that it is convenient, vivid informative and interesting, can greatly improve the efficiency of teaching, but the improvement of teaching effects did not achieve the desired level. Therefore, how to reasonably, effectively use the multimedia resources and really improve the teaching effect becomes a topic which is worth of discussion. Some scholars had completed some researches in a certain extent [1-6], but normally, they discussed them abstractly. Targeted study is lacking, which is really meaningful. In this paper, the author studied the issue exploringly through questionnaire survey. 


\section{Research Methods}

\subsection{Design of research scheme}

The author used his identity of class adviser, selected five major specialized courses including building architecture(A), mechanics of materials(B), concrete structure $(C)$, civil engineering construction(D) and construction project budget(E), distributed questionnaire to five course teachers and forty-four students in the whole class, then draw the research conclusions from statistics and analysis of questionnaire survey results.

\subsection{Design of questionnaire}

The course teachers and students used same questionnaire for receiving survey results in different viewpoint. For every course, the following seven same questions were planned, and respondents were asked to select themselves answer.

Qu.1 : In this course, what is the teaching method being adopted? Please make your choice in (a. multimedia teaching; b. traditional teaching; c. combination of aforementioned two).

Qu.2: In the teaching process, how is the interaction between teachers and students? Please make your choice in (a. good; b. general; c. bad).

Qu.3 : For teaching effect, what is your evaluation to this course? Please make your choice in (a. good; b. general; c. bad).

Qu.4 : For ensuring the teaching effect, which is your expectation in teaching method? Please make your choice in (a. multimedia teaching; b. traditional teaching; c. combination of aforementioned two).

Qu.5 : Do you think multimedia teaching can replace the method of traditional? Please make your choice in (a. yes; b. no).

Qu.6 : (This question is suitable for multimedia teaching only.) How is the quality of teaching courseware in this course? Please make your choice in (a. good; b. general; c. bad).

Qu.7 : (This question is suitable for multimedia teaching only.) How to organize teaching activities in this course when the multimedia teaching system is brokendown? Please make your choice in (a. writing on the blackboard; b. organize student self-study; c. suspend classes).

\subsection{Statistics of survey result}

Author completed the frequency statistics according to selection results of five teachers and forty-four students (The result of teachers see table 1 and students see table 2). 
Table 1. The survey result of teachers

\begin{tabular}{|c|c|c|c|c|c|c|c|c|c|c|c|c|c|c|c|c|c|c|c|c|}
\hline \multirow{2}{*}{ Courses } & \multicolumn{3}{|c|}{ Qu.1 } & \multicolumn{3}{|c|}{ Qu.2 } & \multicolumn{3}{|c|}{ Qu.3 } & \multicolumn{3}{|c|}{ Qu.4 } & \multicolumn{2}{|c|}{ Qu.5 } & \multicolumn{3}{|c|}{ Qu.6 } & \multicolumn{3}{|c|}{ Qu.7 } \\
\hline & $a$ & $b$ & $c$ & $a$ & $b$ & $c$ & $a$ & $b$ & $c$ & $a$ & $b$ & $c$ & $a$ & $b$ & $a$ & $b$ & $c$ & $a$ & $b$ & $c$ \\
\hline A & - & & & & • & & - & & & • & & & • & & & • & & & • & \\
\hline B & & • & & & - & & & - & & & • & & & - & & & & & & \\
\hline C & & - & & & • & & & - & & • & & & • & & & & & & & \\
\hline D & & & - & & - & & & - & & & & - & & - & & - & & - & & \\
\hline E & • & & & & • & & - & & & • & & & - & & & • & & & & - \\
\hline
\end{tabular}

Table 2. The survey result of students

\begin{tabular}{|c|c|c|c|c|c|c|c|c|c|c|c|c|}
\hline \multirow{2}{*}{ Courses } & \multicolumn{3}{|c|}{ Qu.1 } & \multicolumn{4}{c|}{ Qu.2 } & \multicolumn{4}{c|}{ Qu.3 } & \multicolumn{3}{c|}{ Qu.4 } \\
\cline { 2 - 15 } & $\boldsymbol{a}$ & $\boldsymbol{b}$ & $\boldsymbol{c}$ & $\boldsymbol{a}$ & $\boldsymbol{b}$ & $\boldsymbol{c}$ & $\boldsymbol{a}$ & $\boldsymbol{b}$ & $\boldsymbol{c}$ & $\boldsymbol{a}$ & $\boldsymbol{b}$ & $\boldsymbol{c}$ \\
\hline $\mathrm{A}$ & 44 & & & 2 & 14 & 28 & 5 & 26 & 13 & 12 & & 22 \\
\hline $\mathrm{B}$ & & 44 & & 3 & 17 & 24 & 12 & 17 & 15 & 5 & 21 & 18 \\
\hline $\mathrm{C}$ & & 44 & & & 9 & 35 & 8 & 25 & 11 & 11 & 10 & 23 \\
\hline $\mathrm{D}$ & 26 & & 18 & 9 & 22 & 13 & 19 & 18 & 7 & 19 & & 25 \\
\hline $\mathrm{E}$ & 37 & & 7 & 3 & 15 & 26 & 14 & 21 & 9 & 22 & 2 & 20 \\
\hline
\end{tabular}

Continued from Table 2

\begin{tabular}{|c|c|c|c|c|c|c|c|c|}
\hline \multirow{2}{*}{ Courses } & \multicolumn{2}{|c|}{ Qu.5 } & \multicolumn{3}{c|}{ Qu.6 } & \multicolumn{3}{c|}{ Qu.7 } \\
\cline { 2 - 9 } & $\boldsymbol{a}$ & $\boldsymbol{b}$ & $\boldsymbol{a}$ & $\boldsymbol{b}$ & $\boldsymbol{c}$ & $\boldsymbol{a}$ & $\boldsymbol{b}$ & $\boldsymbol{c}$ \\
\hline $\mathrm{A}$ & 31 & 13 & 8 & 21 & 15 & 2 & 17 & 25 \\
\hline $\mathrm{B}$ & 16 & 28 & & & & & & \\
\hline $\mathrm{C}$ & 21 & 23 & & & & & & \\
\hline $\mathrm{D}$ & 37 & 7 & 11 & 24 & 9 & 13 & 10 & 21 \\
\hline $\mathrm{E}$ & 33 & 11 & 5 & 16 & 23 & 3 & 12 & 29 \\
\hline
\end{tabular}

\section{Analysis of Present Situation and Disadvantage in Multimedia Teaching}

We can easily get the conclusion through the questionnaire survey result abovementioned, multimedia teaching has following problems at the moment.

\subsection{Deviation on cognition}

Many teachers have deviations on cognition to multimedia teaching, such as some teachers mistakenly think that they can give up the traditional teaching because of with multimedia, and some one-sided consider it is only the PPT courseware in multimedia teaching, and so on. These deviations cause the consequence of multimedia teaching equipment has not been effectively used, poor quality of the courseware, and the teaching effect can't be achieved the expected level. 


\subsection{Blindness on establishment and using}

Because that the multimedia teaching has been regarded as a very important indicator in evaluation of teaching level, almost all schools and education institutions invest blindly in building multimedia classroom and encourage the multimedia teaching, in order to meet the target. Many teachers "rush" blindly require the use of multimedia, regardless of the course feature need or not, no matter of the teaching effect and student's satisfaction. The limited multimedia resources are occupied as thus, it will certainly cause the multimedia equipment can't be truly effective use.

\subsection{Reducing on teaching skills of teachers}

Many teachers rely too much on multimedia, multimedia courseware even can be used to mask and make up some problem such as inadequate preparation for lessons, sciolism about partial content, etc. They don't pay attention to the basic training of language, blackboard writing and demonstration in the traditional teaching, so their ability to control the classroom is poor, adaptability to changes bad, who certainly can't adapt to the change of teaching environment. For example, once the classroom fall in with the failure of electricity supply, or multimedia system failures, and some else abnormal situation, they will unable to go on the normal teaching and only suspend temporarily.

\subsection{Poor quality on Multimedia teaching software}

At present, although there are a few existing, and available network courseware or commercial teaching software, but the quantity, applicability especially, can't satisfy to our wants. In multimedia teaching, the courseware is still prepared mainly by teachers. But a great number of courseware which is manufactured by teachers are lack of scientificity, the inevitable result is "advanced in teaching methods and poor in teaching effect". This is a key factor of affecting the effects of multimedia teaching.

The poor quality of the courseware mainly embodied in the following aspects:

1. Too simple in production. Some courseware just move the book content to the computer screen by using PowerPoint, even knowledge system is incomplete, not enough system.

2. Break away from the textbook. Some courseware may be better to use multimedia technique and the level of courseware itself is higher, but can't embody textbook content very good, even empty, indefinite on topic, and disordered on gradation.

3. Lack of application of Multimedia functions. Some courseware may be better in refining and summarizing the book content, but cannot effectively use the various functions of multimedia software. Such as no action, no picture or no audio-visual and so on, like thus only display the page-text make the class boring.

4. No update in using of the courseware. Many teachers don't pay attention to update the multimedia courseware even for several years, make it go away from the 
knowledge update and development. Some teachers even no longer prepare lessons before entering the classroom, multimedia became the tools of lazy fellow.

5. Blind pursuit of information quantity. Some teachers search a lot of information from the Internet and put them into the courseware without being selected and treated, directly be showed in class, the students can't grasp the key points.

6. Lack of scientific and effective teaching design. Many multimedia courseware present the content simply without any suspense, take everything in one glance, have no effectively setting up of learning situation for students, and be lack of design in guiding students to think or solve problems, unable to arouse the enthusiasm of learning for most of students.

In addition, there are some unreasonable problems on production of multimedia courseware, such as colors, font size, volume, and so on, these will also affect teaching effect and the learning state of students.

\subsection{Mechanization in teaching process and lack of interaction}

Multimedia teaching will reduce the humanism in the process of teaching. Teaching content and rhythm carry out according to the courseware which is prepared before class. Many teachers in the classroom "discuss in state of sitting", "retell the book according to screen", have no a bit of personality or passion. Teachers speak in sitting and students listen in sitting, the class atmosphere is rigid, there is no effective communication and interact between teacher and students. Students generally reflect the teaching is boring, the teaching effect is poor. The classroom environment like thus become the crucial factors that influence multimedia teaching effect.

\section{Countermeasures and Suggestions for Improving the Multimedia Effectiveness}

\subsection{Correct understanding and rational treatment the form of multimedia teaching}

No matter which one teaching form, the ultimate goal all is to improve the teaching effect and guarantee the teaching quality. Multimedia teaching is another definition for computer-assisted instruction, it's in order to improve teaching efficiency and teaching effect. Multimedia teaching is advanced, but it is just a kind of assistant teaching tools, it can't take place of the traditional teaching. Multimedia teaching has also its shortcomings, we can't totally repudiate the traditional teaching methods. Multimedia teaching is not only a simple PPT courseware teaching, should also include all the various types of files and function can be used for auxiliary teaching, such as audio, video, animation, etc. 


\subsection{Reasonable configuration and distribution of multimedia teaching resources}

Whether to use multimedia teaching or not should be determined according to the nature and characteristics of the course, we should avoid use multimedia blindly. In fact, not all courses are suitable for multimedia teaching, and also not every section is suitable for multimedia teaching in one course. The number and distribution of Multimedia classrooms should be determined on the basis of investigating and surveying appropriately, to ensure the using value of multimedia resources. During the running of the teaching, several multimedia classrooms should be reserved for meeting the temporary needs of some curricula or equipment maintenance. Multimedia resources can really be used effectively just in this way.

\subsection{Improve the quality of multimedia teaching courseware}

Teachers in addition to master professional knowledge, must also be able to master the production and application technology of multimedia. Teachers should participate in the producing of multimedia courseware personally, at the same time, strengthen the construction of teaching team, develop the multimedia courseware collectively, cooperate to solve complex problems in aspects of teaching content, teaching mode, and so on. In producing process of courseware, the teaching process should be carefully designed, be artistic and rational, such as the teaching content should be shown at when, where and in what way, pay attention to create suitable situation. We should fully use the functions of multimedia technology, for instance, using the link technology to contact teaching content with the related content. According to the characteristics and content of courses, to apply comprehensively all kinds of media files, create illustrated, audio-visual, clear, vivid courseware.

\subsection{To strengthen the teaching skill training}

Multimedia teaching demands teachers have good operation ability of hardware and software, and make full use their functions. Such as audio, video, animation, pointers, drawing pen, and even using software on-site and real-time input related content, and so on, those are all beneficial to attract the attention of students and guide students the train of thought.

Teachers should control reasonable lecture rhythm and page conversion speed, make it correspond to the student's acceptance, give students a certain thinking and reaction time. At the same time, in the multimedia teaching, the teacher still have to pay attention to the rational use of language arts and blackboard writing, continue to strengthen the teaching skill training, to cope with the existence of a variety of teaching environment and improve the quality of teaching. 


\subsection{Increase interaction and emotional communication}

Teaching depends on the interaction between teachers and students. It is not only the flow of knowledge, also the emotional communication between teachers and students, even students and students. Teachers' body language and blackboard writing process communication are both irreplaceable. The significance of teacher to students is not multimedia display will be able to complete.

In the process of multimedia teaching, teachers should always pay attention to the emotion of all students. The lecture must to be passionate, and teacher should be good at actively regulating the classroom atmosphere, promoting the exchanges of teachers and students by the personality charm, through emotional influence between teachers and students.

\subsection{Pay attention to the combination of multimedia teaching and traditional teaching}

Each of teaching form has its own advantages and disadvantages, we only learn the essence of all kinds of teaching methods and means, optimize and comprehensively apply them. Only in this way, we can really improve the teaching effect. Multimedia teaching should be organically combined with the advantages of traditional teaching means, and timely switch in the two kinds of teaching methods to make them into supplement each other. Blackboard writing and body language of teacher are also indispensable in multimedia teaching, for example, the reasoning process of important and difficult contents should be lectured by necessary blackboard writing. For problems, solution and conclusion, flexible use of multimedia technology is better than traditional teaching means, we can combine picture, text, sound, video and show the dynamic change process, to deepen the students' impressions and memory and achieve the best teaching effect.

\subsection{Establish the supervision system for multimedia teaching}

Management departments should strengthen the management of teaching quality and carry out quality evaluation of multimedia teaching. The effective supervision system should be established, such as the maintenance and management of multimedia hardware environment, the using training of multimedia teaching equipment, the guidance of fabrication and application for multimedia courseware, as well as the quality standard and evaluation of multimedia classroom teaching. This can not only stimulate the enthusiasm of the teachers in multimedia teaching, create a good environment for teachers in improving multimedia teaching ability, and promote the effectiveness of multimedia teaching. 


\section{Conclusions}

Multimedia teaching is a kind of advanced teaching form with advantages of intuitive, vivid, informative, interesting and many other. It has incomparable advantages against traditional teaching means and can greatly improve teaching efficiency, but we should also realize its shortcomings at the same time. The traditional teaching and multimedia teaching must be organically combined as auxiliary and supplement each other, only this can receive the teaching effect of getting twice the result with half of the effort.

Management department shall establish perfect monitoring system of teaching quality and evaluation system of multimedia teaching, strengthen the management and guidance for multimedia teaching.

Teachers should be active in learning to master modern technology and teaching theory, assiduously train our education teaching art, improve the fabricating level of courseware, pay attention to the organization and control of classroom, think highly of the emotional communication between teachers and students.

Management departments, teachers and students should make joint efforts together to get rid of the current plight of the multimedia teaching, guarantee the effectiveness of the multimedia, and achieve the optimization in using and teaching effect of multimedia.

\section{Acknowledgment}

This work was supported by the Scientific and Technological Research Project of Hubei Provincial Department of Education, China (Project Number is B2016276).

\section{$7 \quad$ References}

[1] Lu Xiaoling, Jin Guofang, "The Integration of Traditional and Modern Teaching Measures in Multi-media Teaching", Vocational and Technical Education(Teaching Research), 2006, Volume 27, Number 17, Pages 64-65.(in Chinese)

[2] Miao Liping, Discuss on the problem of multimedia validity in colleges and universities, Heilongjiang Researches on Higher Education,2010, Number 6, Pages 165-166. (in Chinese)

[3] Sun Xianming, Fu Yanfeng, "The problems existing in the multimedia teaching and countermeasures”, Education Exploration,2006, Number 9, Pages 47-48. (in Chinese)

[4] Lisa Daniels, "Introducing technology in the classroom: PowerPoint as a first step", Journal of Computing in Higher Education, 1998, Volume 10, Number 2, Pages 42-56. https://doi.org/10.1007/BF02948722

[5] Albert L. LeDuc, "What is truly important about information technology in higher education", Journal of Computing in Higher Education, 1996, Volume 8, Number 1, Pages 124139. https://doi.org/10.1007/BF02942399

[6] Russell J. Craig and Joel H. Amernic, "PowerPoint Presentation Technology and the Dynamics of Teaching", Innovative Higher Education, 2006, Volume 31, Number 3, Pages 147-160. https://doi.org/10.1007/s10755-006-9017-5 
Paper-Study on Effective Using of Multimedia Teaching System and Enhancing Teaching Effect

\section{Author}

Xianhong Xu is a teacher of the School of Civil Engineering and Architecture, Hubei Polytechnic University, China.

Article submitted 3 July 2016. Published as resubmitted by the author 11 April 2017. 